\title{
PREVALENCE OF DEVELOPMENTAL DEFECTS OF ENAMEL AMONG 16-YEAR-OLD CHILDREN IN MALAYSIA
}

Nik-Hussein NN, Majid ZA, Mutalib KA, Abdullah, F, Abang $A$, Wan MN.. Prevalence of developmental defects of enamel among 16-year-old children in Malaysia. Annal Dent Univ Malaya 1999; 6: 11 - 16

\section{ABSTRACT}

The prevalence of developmental defects of enamel was assessed in 4805 16-year-old schoolchildren in fluoridated and non-fluoridated areas in Malaysia. In this sample, the mouth prevalence was $56.0 \%$; tooth prevalence was $21.8 \%$. There were significant differences between children in fluoridated and non-fluoridated areas, urban and rural areas as well as between the ethnic groups. However, there was no significant gender difference. Prevalences were lower than those reported in most other Asian countries. However, direct comparisons could not be made due to differences in indices and methodology used.

KEYWORDS: Enamel defects, developmental defects, mouth prevalence and tooth prevalence.

\section{INTRODUCTION}

Malaysia comprised of two regions, Peninsular Malaysia, which is popularly known as West Malaysia and East Malaysia. Peninsular Malaysia consists of 12 states while East Malaysia consists of the two states of Sabah and Sarawak, which are located on the island of Borneo. The two regions are separated by the South China Sea.

The public water supplies in most areas in Peninsular Malaysia and Sarawak are fluoridated. This was the result of positive findings from the public water fluoridation programme, which was first started in Johore Bharu in 1957(1). In 1972, the Malaysian Cabinet passed a federal policy to fluoridate public water supplies in the country(2). Since then approximately $66.8 \%$ of the population in Peninsular Malaysia and Sarawak receive fluoridated water(3). However, with the exception of water supplies to the Federal territory of Labuan, there is no fluoridation of community water supplies in the state of Sabah.

Several epidemiological surveys on oral health of schoolchildren have been conducted in Malaysia since 1970(4-7), where the main focus of the surveys was directed towards dental caries and not much emphasis was given to enamel defects. More recently however, as a result of increased awareness and concern over the defects of dental enamel, especially in relation to fluoride uses, several studies have been conducted specifically to look into the prevalence of DDE in the states of Johore $(8,9)$, Selangor(10) and Penang(11,12). All these studies indicated that the prevalence of enamel defects among children in these areas are above $70 \%$. Due to high prevalence in these areas, it was therefore decided that as part of the National Oral Health Survey of School Children (1997), enamel defects among school children will be examined in order to determine the prevalence of DDE
*Nik-Hussein NN, +Majid ZA, \#Mutalib KA, \#Abdullah F, \#Abang A and \#Wan MN

*Department of Children's Dentistry and Orthodontics, Dental Faculty, University of Malaya, 50603 Kuala Lumpur

+ Formerly Professor of Children's Dentistry, Dental Faculty, University of Malaya \# Oral Health Division, Ministry of Health, Malaysia

* Name and address of author to whom requests for reprints should be addressed.

among Malaysian children and also to provide baseline for monitoring such defects.

\section{MATERIALS AND METHOD}

Study subjects were children aged 16 years old and studying in government or government-assisted schools. A complete list of these schools was obtained from the Ministry of Education, Malaysia. In 1997, a total of 318,703 children met these criteria. About $1.3 \%$ of these children was drawn as sample subjects for this study.

A multi-stages stratified random sampling method was used. The schools formed the sampling frame and the school children formed the sampling units. The schools were classified by geographical location and the children were classified according to gender and ethnicity.

From each selected school, the classes were randomly selected from the school register. All the children in the selected classes were included in order to minimise disruption of lessons.

Regional and racial distribution of the sample did not closely follow the national distribution, as there was a slight compensation in the proportion of subjects from Sabah and Sarawak and also among Kadazan, Ibans and Other Bumiputras(indigenous groups) in order to obtain significant numbers

Clinical examinations were carried out in the classroom by using a portable Waldman operating light with the patient seated on a portable dental chair and the examiner seated on a portable stool behind the subject. The teeth were not dried but gauze was used to remove oral debris when necessary.

The buccal surfaces of all fully erupted teeth were examined using the modified DDE index based on the recommendations made in 1992 by the FDI working group on developmental defects of enamel index(13). The scores were called out by the examiner and recorded by a recorder, onto a specially prepared form. The sequence of examination was from maxillary right second molar to maxillary left second molar; mandibular left second molar 
Table 1: Sampling frame and subjects examined

\begin{tabular}{|c|c|c|c|c|}
\hline \multicolumn{2}{|r|}{ VARIABLE } & SAMPLING FRAME & SUBJECTS EXAMINED & $\%$ \\
\hline \multirow[t]{2}{*}{$\overline{\text { GENDER }}$} & Male & 151076 & 1972 & 1.3 \\
\hline & Female & 167627 & 2113 & 1.3 \\
\hline \multirow{7}{*}{$\begin{array}{l}\text { ETHNIC } \\
\text { GROUPS }\end{array}$} & Malay & 193089 & 2376 & 1.2 \\
\hline & Chinese & 74813 & 930 & 1.2 \\
\hline & Indian/Pakistani & 19956 & 237 & 1.3 \\
\hline & Kadazan & 5970 & 87 & 1.5 \\
\hline & Iban & 4954 & 98 & 2.0 \\
\hline & Other Bumiputra & 16396 & 299 & 1.8 \\
\hline & Others & 3183 & 38 & 1.2 \\
\hline \multirow[t]{3}{*}{ REGION } & Pen. Malaysia & 272062 & 3268 & 1.2 \\
\hline & Sarawak & 23543 & 495 & 2.1 \\
\hline & Sabah & 23098 & 322 & 1.4 \\
\hline \multicolumn{2}{|r|}{ MALAYSIA } & 318703 & 4085 & 1.3 \\
\hline
\end{tabular}

to mandibular right second molar. Missing, crowned, unerupted, severely fractured or grossly carious teeth involving the buccal/labial surface of the teeth were recorded and excluded from analysis.

At the end of every working day, the data were entered onto a software programme designed for the purpose of this survey. The data were subsequently processed and analysed using the EPI INFO 6 and the SPSS statistical software programmes.

\section{Survey team and calibration}

As the subjects for this survey were distributed over an area of over 320,000 sq. km, 13 dental officers were involved in the clinical examination of the children and 13 dental surgery assistants were recorders. Calibration and standardisation exercises were done prior to the survey and the results of inter-examiner agreement were as previously reported(14).

\section{RESULTS}

The distribution of subjects according to gender, ethnic groups and region is as shown in Table 1 . The subjects examined formed $1.3 \%$ of the 16-year-old from government and government-assisted schools.

A total of 4085 subjects were examined, of which 1972 (48.3\%) were males and 2113 (51.7\%) were females. The largest number of subjects examined were Malays $(58.2 \%)$, followed by Chinese $(22.8 \%)$. The rest of the subjects were made up of other indigenous groups which accounted for $7.3 \%$ of the sample, Indians/Pakistanis (6.3\%), Ibans (2.4\%), Kadazans (2.4\%) and other ethnic groups $(0.9 \%)$.

\section{Mouth and tooth prevalence}

2289 children $(56 \%)$ examined had at least one tooth with enamel defects. There were 1126 affected males and 1163 affected females. The prevalence of the affected males was
Figure 1: Prevalence of developmental defects of enamel by region

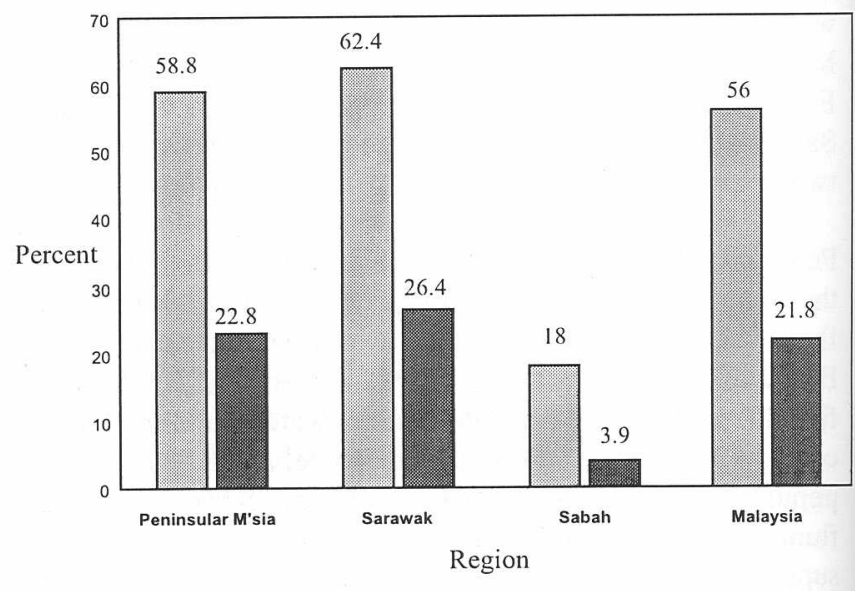

$\square$ Mouth Prevalence

$57.1 \%$ as compared to $55 \%$ in females. There was no statistically significant gender difference with respect to enamel defects; thus subsequent data between gender have been combined.

A total of 111,857 teeth were included in the study of which 24385 teeth showed the presence of enamel defects i.e. a tooth prevalence of $21.8 \%$.

\section{Region}

The prevalence of enamel defects for Peninsular Malaysia was $58.8 \%, 62.4 \%$ for Sarawak and $18 \%$ for Sabah. Similarly, the tooth prevalence was also highest in Sarawak and lowest in Sabah (Fig. 1). The difference between Peninsular Malaysia and Sabah, and Sarawak and Sabah were statistically highly significant, but the difference between Peninsular Malaysia and Sarawak being statistically non-significant. 
Table 2: Mouth and tooth prevalence according to area

\begin{tabular}{|l|c|c|c|c|}
\hline Types of Defects & \multicolumn{2}{|c|}{ Fluoridated } & \multicolumn{2}{c|}{ Non-Fluoridated } \\
\hline & Mouth Prevalence* & Tooth Prevalence \\
$\mathrm{n}=2,195$ & $\mathrm{n}=18,590$ & Mouth Prevalence* & $\mathrm{n}=1639$ & $\mathrm{n}=4,300$ \\
\hline Demarcated Opacity & 21.5 & 1.4 & 6.4 & 0.4 \\
\hline Diffuse Opacity & 67.4 & 28.5 & 35.8 & 8.8 \\
\hline Hypoplasia & 7.5 & 0.4 & 3.1 & 0.2 \\
\hline Combination of Defects & 6.2 & 0.4 & 1.5 & 0.2 \\
\hline Any Other Defects & 0.1 & 0.01 & 0.2 & $\mathbf{3 8}$ \\
\hline ANY DEFECTS & $\mathbf{6 9 . 6}$ & 30.7 & 3.6 & 9.7 \\
\hline
\end{tabular}

* The frequencies in each category were not mutually exclusive.

\section{Area (fluoridated and non-fluoridated)}

Schools were stratified into fluoridated and nonfluoridated areas based on the water supply to the respective schools. Of the subjects examined, 2,195 $(53.7 \%)$ were from fluoridated areas and 1,639 (40.1\%) were from non-fluoridated areas. Designation of whether areas were fluoridated or non-fluoridated could not be ascertained for 251 children $(6.1 \%)$ as the water supply to the school could not be ascertained.

With the exception of any other types of defects, mouth prevalence of all types of defects was higher in fluoridated areas than non-fluoridated areas. Diffuse opacities was the most prevalent type of defect observed and it was found in $67.4 \%$ of children in fluoridated areas as compared to $35.8 \%$ non-fluoridated areas (Table 2).
Diffuse opacity was also the most prevalent type of defect affecting affected teeth, occurring more than three times in fluoridated areas than non-fluoridated areas.

The mouth and tooth prevalence of enamel defects between fluoridated and non-fluoridated areas were highly significant.

\section{Prevalence of affected tooth}

Figure 2 shows the prevalence of developmental defects of enamel for each of the 28 teeth. teeth. Enamel defects was more prevalent in the maxillary teeth than the mandibular teeth. The maxillary first premolar showed the highest prevalence $(32.7 \%)$ and the least affected were the mandibular incisors. With the exception of the second molars, the tooth prevalence of posterior teeth was higher than the anterior teeth.

Figure 2: The percentage prevalence of developmental defects of enamel for each of 28 teeth

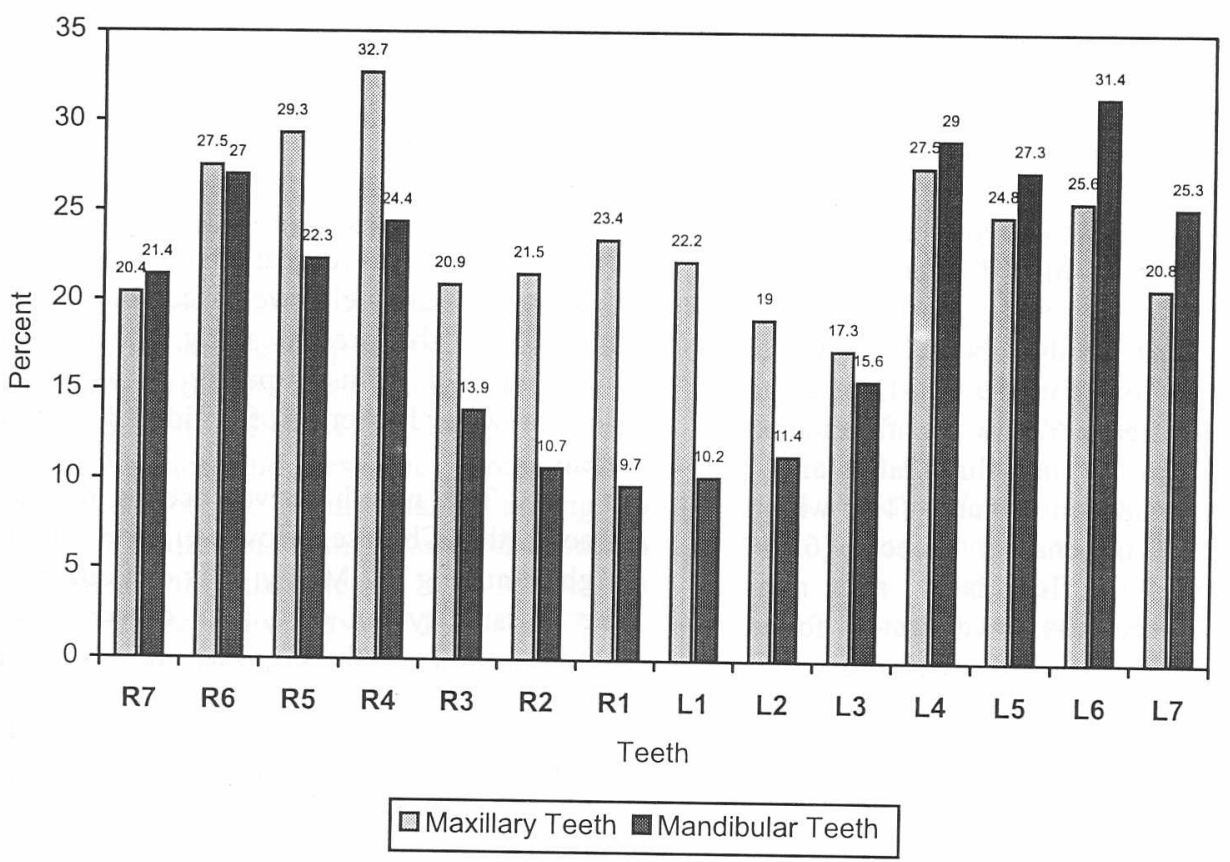




\section{Ethnic Groups}

Chinese showed the highest prevalence of enamel defects with over $64 \%$ of the subjects affected. Among the Malays, a prevalence of $57.5 \%$ was noted. The prevalence of enamel defects among the Indian/Pakistanis is $54.5 \%$, among Ibans is $52 \%$ and among other Bumiputras is $37.5 \%$. The Kadazans were the least affected with a prevalence of $9.2 \%$ (Fig.3). Enamel defects differ very significantly between ethnic groups.

\section{Discussion}

Over the last 30 years, numerous studies have been conducted and reported in different populations regarding the developmental defects of dental enamel(1528). Several indices were used, either based on presumed aetiology or based solely on simple description of the clinical appearance of the lesion. Thus, direct comparisons of these results are difficult.

The most widely used index is the developmental defect of dental enamel (DDE Index)(29). This index was developed by the Commission on Oral Health, Research and Epidemiology of the FDI in order to overcome the need to arrive at a diagnosis of enamel defect on the basis of presumed aetiology. This index had been reviewed and modified for use in general purposes epidemiological study. The DDE index is now well-accepted among researchers and its use is also well established, especially after the index was reviewed(13), which has simplified data collection and analysis.

The mouth prevalence of enamel defects in this study is $56.0 \%$. As different indices were used in previous epidemiological studies in Malaysian children, the results of the present study are not directly comparable to those earlier surveys. In the 1970-1971 survey (4), Dean's Index of dental fluorosis was used and it was reported absent. The modified Dean's index was used in subsequent surveys (5-7) and the prevalence of defects among 16year-old children in Peninsular Malaysia and Sabah was $23.5 \%$ and $10.4 \%$ respectively. Thus, the prevalence observed in the present study is much higher than previously reported. An increase in prevalence of enamel defect have also been reported by other workers in other countries $(15,16,20,22,27,28)$ and possible contributing factors that have been suggested by other researchers are inappropriate use of fluoride supplements, ingestion of fluoridated toothpaste, increase amount of fluoride in food and atmosphere.

The results of this study showed that the prevalence of DDE is much lower in the non-fluoridated areas than the fluoridated areas, $69.6 \%$ for fluoridated areas as compared to $38.6 \%$ for non-fluoridated areas. With the exception of a study in Ireland (16) which reported similar prevalence of enamel defects (63\%) among 15-year-olds living in fluoridated and nonfluoridated areas, almost all the other investigators found lower prevalence in the non-fluoridated areas. However, the mouth prevalence of DDE in this study for fluoridated as well as non-fluoridated area is much lower than those reported by other countries $(22,26,28)$. The mouth
Figure 3: Prevalence of developmental defects of enamel by ethnic groups

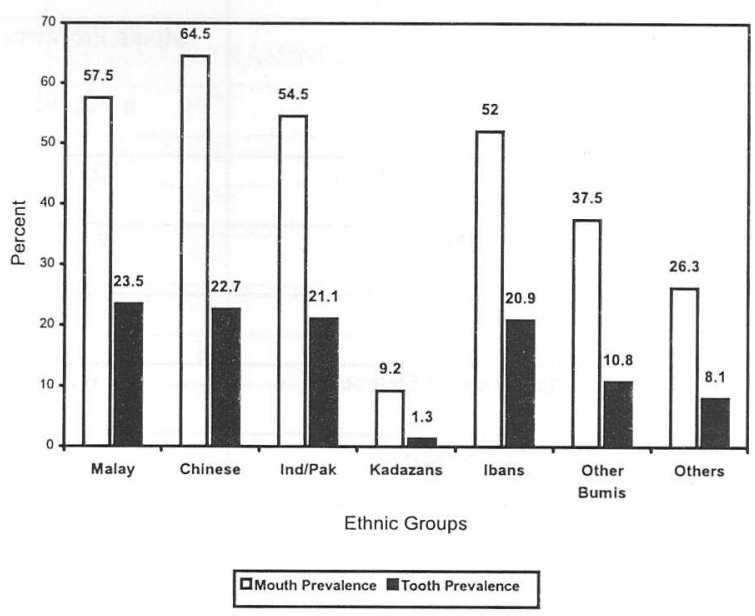

prevalence of $69.6 \%$ for children living in fluoridated areas observed in this study is almost equal to the prevalence of $69.0 \%$ reported among 12- to 14-year-old New Zealand children (26) residing in low fluoride areas $(<0.21 \mathrm{ppm})$. It is also much lower than the prevalence of enamel defects among Hong Kong, Singaporean or Saudi children. Studies in Hong Kong reported a prevalence of $94.0 \%$ for 20 -year-olds and a prevalence of over $99.6 \%$ for 12-year-olds. Among 16-year-old Singaporean children(27), a prevalence of $84.6 \%$ was reported and among 14-year-old Saudi males(25), a prevalence of 75.0, 82.0 and $93.0 \%$ were reported for low, medium and high fluoride areas respectively.

Although a wide variety of clinical appearances of enamel defects were observed in this study, the most prevalent type of defect observed in both fluoridated and non-fluoridated was diffuse opacity. Studies $(8,9,27,32)$ had shown that the prevalence of enamel defects, in particular the diffuse opacity was higher in population living in fluoridated areas and that the tooth prevalence of diffuse opacity was about 2-3 times greater among children in fluoridated than non-fluoridated areas. Clarkson and O'Mullane(16) also reported that while the prevalence was similar among children living in fluoridated and non-fluoridated areas in Ireland, the prevalence of diffuse opacities was higher among children in fluoridated areas. In contrast, it was reported that other types of defects (demarcated opacity, hypoplasia and discoloured enamel) were equally prevalent in both areas(8). In the present study, it was observed that the prevalence of diffuse opacity as well as other types of defects were higher in fluoridated than non-fluoridated areas.

The mouth prevalence in this study is highest among the Chinese. However, the tooth prevalence is highest among the Malay. It is difficult to explain this but the possibility of diet and other cultural differences between the two ethnic groups may contribute to this. The mouth and tooth prevalence is lowest among the Kadazans. This is not surprising as the Kadazans generally reside in the state of Sabah; where with the exception of 
the water supply to the Federal Territory of Labuan, other areas of the state is non-fiuoridated.

\section{ACKNOWLEDGEMENTS}

We are grateful to Drs. Che' Zainiah Mansor, Wardati Abdul Malik, Malliga a/p Palanisamy, Fatimah Saad, Chew Yoke Yuen, Vijaya Manohar a/l Kanagalingam, Loh Kim Hong, Su Kien Looi, Radhakrishnan a/l Nadarajah, Azizah Yusoff, Ragunandhanan a/l Menon, Andrew Eddy and Yaw Siew Lian who carried out the examinations. We thank Dr. Varatha Raju for his assistance with the analysis of the data and Ministry of Science and Technology, Malaysia under the Intensification of Research in Priority Areas (IRPA) for financial support.

\section{REFERENCES}

1. Report of the Committee appointed to enquire into and report upon the fluoridation of public water supplies in West Malaysia. Dental Division, Ministry of Health, Malaysia, 1972.

2. Fail KKM. Bil 164/811/72, Ministry of Health, Malaysia, 18 April 1972.

3. Laporan Pemfluoridaan, Ministry of Health, Malaysia, 1998.

4. Dental Epidemiological survey of schoolchildren in West Malaysia 1970-1971. Dental Division, Ministry of Health, Malaysia, 1972.

5. Dental epidemiological survey of schoolchildren in Sabah. Dental Division, Ministry of Health, Malaysia 1986.

6. Dental Epidemiological survey of schoolchildren in Sarawak. Dental Division, Ministry of Health, Malaysia 1982.

7. Dental Epidemiological survey of schoolchildren in Peninsular Malaysia, Dental Division, Ministry of Health, Malaysia 1988.

8. Epidemiological survey of developmental defects of dental enamel in Johore. Dental Division 1986. Dental Division Johore Malaysia.

9. Majid ZA, Nik Hussein NN, Bagramian RA. The prevalence of caries and developmental defects in an adult population in Malaysia. Dent J Malaysia 1995; 16: 33-9.

10. Nik Hussein NN, Razak IA. The prevalence and distribution of enamel defects in 11-12 year old Malaysian schoolchildren. Ann Acad Med Sing 1989; 18: 591-3.

11. Majid ZA, Nik Hussein NN, Bagramian RA. The prevalence of caries and developmental defects in 229 Malaysian children 16 years after water fluoridation (a pilot study). Sing Dent J 1996; 21:11-15.

12. Sujak SL. Prevalence and aesthetic perception of developmental defects of dental enamel among 16 years-old schoolchildren in Penang. Research report in partial fulfilment for the degree of Master in Community Dentistry, University of Malaya 1997.

13. Federation Dentaire Internationale. Commission on Oral Health Research \& Epidemiology. A review of the Developmental defects of Dental Enamel (DDE Index). Int Dent J 1992; 42: 411-26.
14. National Oral Health Survey of school children 1997 (NOHSS '97). Oral Health Division, Ministry of Health, Malaysia 1998.

15. Angelillo IF, Romano F, Fortunato L, Montanaro D. Prevalence of dental caries and enamel defects in children living in areas with different water fluoride concentrations. Community Dent Health 1990; 7: 229 6.

16. Clarkson JJ, O’Mullane DM. Prevalence of enamel defects/fluorosis in fluoridated and non-fluoridated areas in Ireland. Community Dent Oral Epidemiol 1992; 20: 196-9.

17. Cutress TW, Suckling GW, Pearce EIF, Ball ME. Defects of tooth enamel in children in fluoridated and non-fluoridated water areas of the Auckland Region. NZ Dent J 1985; 81: 12-9.

18. De Liefde B, Herbison GP. The prevalence of developmental defects of enamel and dental caries in New Zealand children receiving differing fluoride supplementation, in 1982 and 1985. NZ Dent J 1989; 85: 2-8.

19. Dummer PMH, Kingdon A, Kingdon R. Prevalence of enamel developmental defects in a group of 11- and 12 -year-old children in South Wales. Community Dent Oral Epidemiol 1986; 14: 119-22.

20. Ellwood RP, O'Mullane DM. The demographic and social variation in the prevalence of dental enamel opacities in North Wales. Community Dent Health 1994; 11: 192-6.

21. King NM, Wei HS. Developmental defects of enamel: a study of 12 years old in Hong Kong. J Am Dent Assoc 1986; 112: 835-9.

22. Nunn JH, Murray JJ, Reynolds P, Tabari D, Breckon J. Prevalence of developmental defects of enamel in 15-16 year old children residing in three districts (natural fluoride, adjusted fluoride, low fluoride) in the north east of England. Community Dent Health 1992; 9: 235-47.

23. Nunn JH, Rugg-Gunn AJ, Ekanayake L, Saparamadu DG. Prevalence of developmental defects of enamel in areas with differing water fluoride levels and socioeconomic groups in Sri Lanka and England. Int Dent J 1994; 44: 165-73.

24. Razak IA, Nik Hussein NN. A study of enamel defects in 11-12-year-old subjects in a fluoridated area. Dent $\mathbf{J}$ Malaysia 1986; 9: 21-8.

25. Rugg-Gunn AJ, Al-Mohammadi SH, Butler TJ. Effects of fluoride level in drinking water, nutritional status, and socio-economic status on the prevalence of developmental defects of dental enamel in permanent teeth in Saudi 14-year-old boys. Caries Res 1997; 31 : 259-67.

26. Sukling GW, Pearce EIF. Developmental defects of dental enamel in a group of New Zealand children; their prevalence and some associated etiological factors. Community Dent Oral Epidemiol 1984; 12: 177-84.

27. Wiktorsson AM, Martinsson T, Zimmerman M. Prevalence of fluorosis and other enamel defects related to caries among adults in communities with 
optimal and low water fluoride concentrations. Community Dent Health 1994; 11: 75-8.

28. Lo GL, Bagramian RA. Prevalence of dental fluorosis in children in Singapore. Community Dent Oral Epidemiol 1996; 24: 25-7.

29. Federation Dentaire International. Commission on Oral Health Research \& Epidemiology. An Epidemiological Index of Developmental Defects of Dental Enamel. Int Dent J 1982; 32: 159-67.
30. Horowitz HS. Fluoride and enamel defects. Adv dent Res 1989; 3: 143-146.

31. Milsom K, Mitropoulos CM. Enamel defects in 8year-old children in fluoridated and non-fluoridated parts of Cheshire. Caries Res 1990; 24: 286-289.

32. Vignarajah S. Dental caries experience and dental opacities in urban and rural areas of Antigua with different levels of natural fluoride in drinking water. Community Dent Health 1993; 10: 159-166. 